\title{
VARICELla PNEUMONIA
}

Sivakumar Srinivasan, MD, Rangadham Nagarakanti, MD and Sandhya Nalmas, MD

44 year old Hispanic male with no significant past medical history, recently discharged from prison, presented to the hospital with rash all over the body with itching. The rash started on the face, at the back of the ear and then spread to the trunk and legs. He denied fever, chills, cough, shortness of breath or sick contacts. Physical examination revealed a young, comfortable looking male with stable vital signs except for a temperature of $102 \mathrm{~F}$. Skin examination was significant for maculo-papular rash (Figures 1 and 2) with vesicles and pustules, some of which were crusted, found diffusely over face, chest, abdomen, and extremities yet sparing the palms and soles. Oral cavity also showed mucosal lesions. The laboratory values included WBC count of $7,700 / \mathrm{mm} 3$ with $78 \%$ segmented neutrophils, Hgb of $15.4 \mathrm{~g} / \mathrm{dL}$, ESR of 13 , creatinine of $0.8 \mathrm{mg} / \mathrm{dL}$, albumin of $3.3 \mathrm{~g} / \mathrm{dL}$, aspartate transaminase of $73 \mathrm{IU} / \mathrm{L}$, alanine

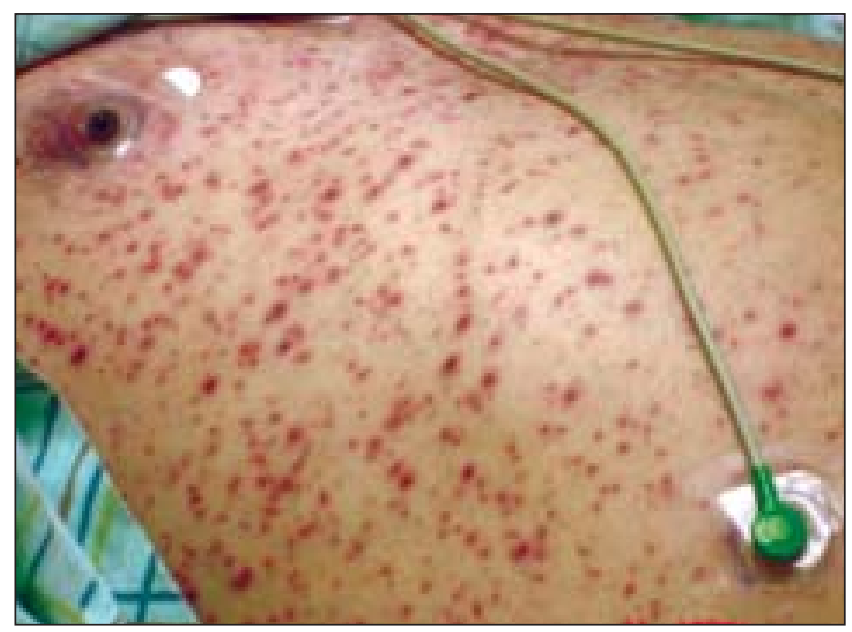

Figure 1. Maculopapular rash with vesicles and pustules on torso.

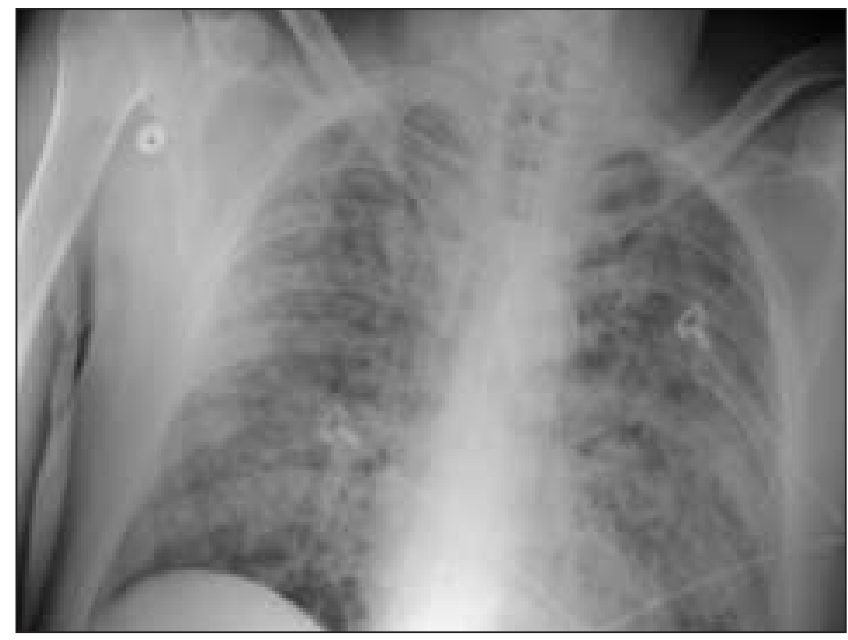

Figure 3. Chest X-ray showing Diffuse Bilateral alveolar infiltrates. transaminase of $70 \mathrm{IU} / \mathrm{L}$, and lactate dehydrogenase of $924 \mathrm{IU} / \mathrm{L}$. Arterial blood gas on room air showed a $\mathrm{PaO} 2$ of 70 . Chest $\mathrm{x}$-ray (Figure 3) showed diffuse bilateral alveolar infiltrates. Chest CT (Figure 4) was significant for wide spread interstitial pneumonia. Serology was positive for varicella zoster $\operatorname{IgM}$ antibodies. The patient was treated with intravenous acyclovir $800 \mathrm{mg}$ every 8 hours for 7 days with excellent clinical improvement and without any adverse sequelae.

\section{References}

1. Mer M Richards GA. Corticosteroids in life threatening varicella pneumonia Chest 114:426-431,1998

2.Emerson L Gasparetto Varicella pneumonia on immunocompetent adults: report of two cases, with emphasis on high resolution computed tomography findings

3. Braz J Infect Dis. 2005 Jun;9(3):262-5.

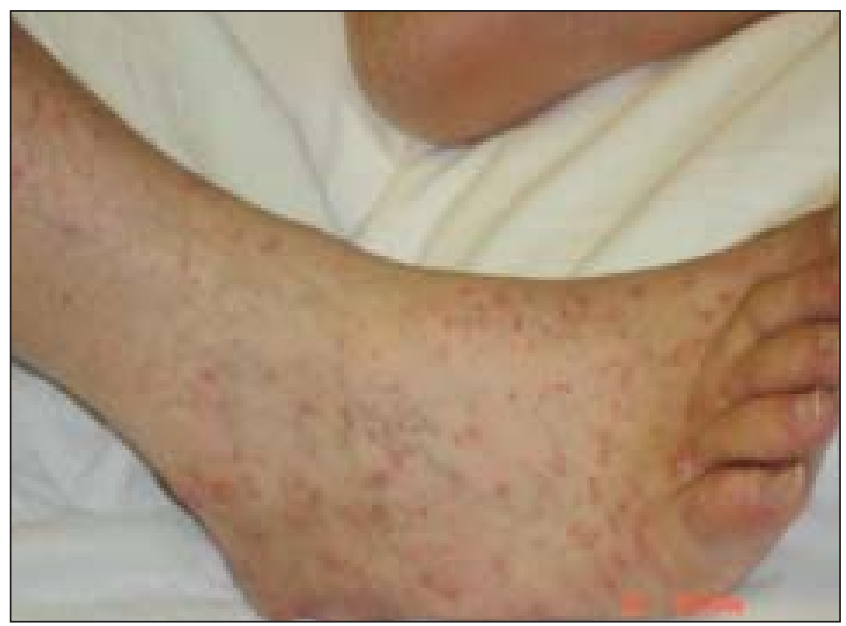

Figure 2. Maculopapular rash on extremities.

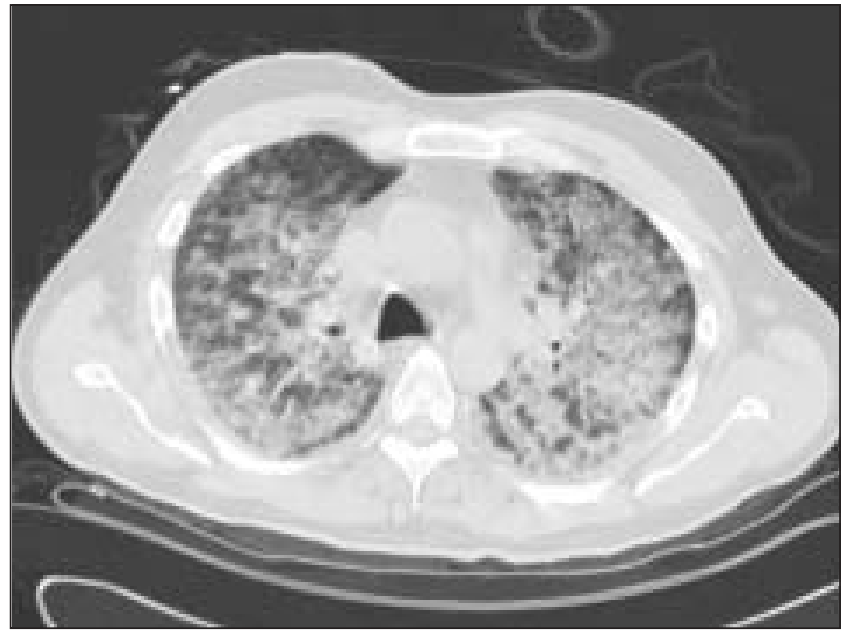

Figure 4. Chest CT showing interstitial pneumonia. 